\title{
(2) OPEN ACCESS \\ Recurrent vaginal cuff dehiscence after surgery for endometriosis: a technique for laparoscopic repair with an omental flap
}

\author{
Gerard-Peter Frank ำ ${ }^{1}$ Johann Rhemrev,${ }^{1,2}$ Marinke Westerterp, ${ }^{3}$ Jim English ${ }^{2}$
}

'Obstetrics and Gynaecology, Medisch Centrum Haaglanden, The Hague, Zuid-Holland, The Netherlands

${ }^{2}$ Endometriose in Balans (referral centre), Medisch Centrum Haaglanden, The Hague, Zuid-Holland, The Netherlands

${ }^{3}$ Surgery, Medisch Centrum Haaglanden, The Hague, ZuidHolland, The Netherlands

Correspondence to

Gerard-Peter Frank;

gpgmfrank@gmail.com

Accepted 5 February 2021
Check for updates

(c) BMJ Publishing Group Limited 2021. Re-use permitted under CC BY-NC. No commercial re-use. See rights and permissions. Published by BMJ.

To cite: Frank G-P Rhemrev J, Westerterp M et al. BMJ Case Rep

2021:14:e239540.

doi:10.1136/bcr-2020-

239540

\section{SUMMARY}

Vaginal evisceration is a rare but severe complication after hysterectomy or colpotomy and is generally successfully repaired by reapproximating healthy tissue edges of the vagina. Recurrent vaginal cuff dehiscence is problematic especially in sexually active women. We describe two cases of recurrent vaginal cuff dehiscence. The first patient had a hysterectomy for endometriosis. The second patient underwent laparoscopic excision of an endometriotic nodule at the vaginal vault. The vaginal cuff dehiscence was repaired by a laparoscopic approach employing an omental flap to enhance tissue healing. This closure technique turned out to be successful at follow-up in both cases. In case of recurrent vaginal cuff dehiscence, management options are limited. Our case report offers a laparoscopic treatment option by using an omental flap. This procedure can be used when conventional repair fails.

\section{BACKGROUND}

We present a successful repair of recurrent vaginal cuff dehiscence by employing an omental flap. The management options for recurrent vaginal cuff dehiscence are limited. Approximation of tissue edges by sutures is the cornerstone of contemporary management. Choosing another method of surgery or suture material probably does not make difference after initial repair fails and lacks evidence. Vaginal mesh is suggested, but patients are reluctant to use mesh materials after well-documented problems with such meshes. Recurrent vaginal cuff dehiscence is problematic especially in sexually active women. That is why employing an omental flap for enhanced tissue healing can be very useful when conventional repair recurrently fails.

\section{CASE PRESENTATION \\ Case 1}

A 37-year-old premenopausal woman underwent a laparoscopic hysterectomy due to endometriosis not responding to conservative treatment. During laparoscopic hysterectomy a monopolar hook was used to open the vagina. A LigaSure device was used to complete the colpotomy. The vaginal vault was closed laparoscopically with a running 3/0 barbed monofilament suture. Standard preoperative antibiotics were administered.

She presented to our tertiary endometriosis centre 5 years after laparoscopic hysterectomy with complaints of deep dyspareunia and abdominal pain. Her medical history was otherwise unremarkable with two spontaneous vaginal deliveries and normal bodyweight (body mass index 20.3). She had no risk factors for impaired wound healing such as cigarette smoking, diabetes or steroid use.

Physical examination, vaginal ultrasound and MRI results indicated the likely presence of a deep endometriotic lesion at the top of the vagina. An uncomplicated laparoscopic resection of the lesion was performed using Sonicision. The vagina was closed laparoscopically using a 2-0 vicryl running suturing technique with clips. According to the local protocol a single dose of cefazolin $2 \mathrm{~g}$ and metronidazole $500 \mathrm{mg}$ were given intravenously just before the induction of anaesthesia for infection prophylaxis. Endometriosis was histologically confirmed.

Six weeks later the patient presented to our emergency department with vaginal pain and a bloody vaginal discharge after sexual intercourse. Examination revealed a vaginal cuff dehiscence. A $3 \mathrm{~cm}$ loop of small intestine was visible in the upper vagina. The intestine showed no signs of ischaemia or laceration and looked vital with healthy peristalsis. Since she came directly to the hospital and no bowel necrosis or injury was suspected, she was treated via a vaginal approach. Simple repositioning of the small bowel was performed. The peritoneum was closed with a vicryl 2-0 running suture. The vaginal cuff was closed by interrupted sutures using vicryl 1-0. A standard single dose of preoperative antibiotic prophylaxis was administered. Shortly after this uneventful procedure she was discharged from hospital.

At postoperative check-up 6 weeks after the second repair, she presented with vaginal cuff dehiscence without evisceration. The vaginal cuff was found to be partly open; the peritoneum was closed but visible. She had not had sexual intercourse since the last surgical repair. Because of her earlier recurrent vaginal cuff dehiscences after sexual intercourse, a second repair was scheduled.

Since the two previous two repairs failed, it was decided to employ a different technique, namely to refresh the vaginal edges and to perform a two-layer closure of the vagina with the subsequent employment of an omental flap.

At laparoscopy, the vaginal cuff and dehiscence were identified and the peritoneum closing the vaginal top identified and opened. The healed tissue at the top of the vaginal cuff was excised with an ultrasonic excision system (Sonicision). The top of the vagina was then sutured with interrupted 


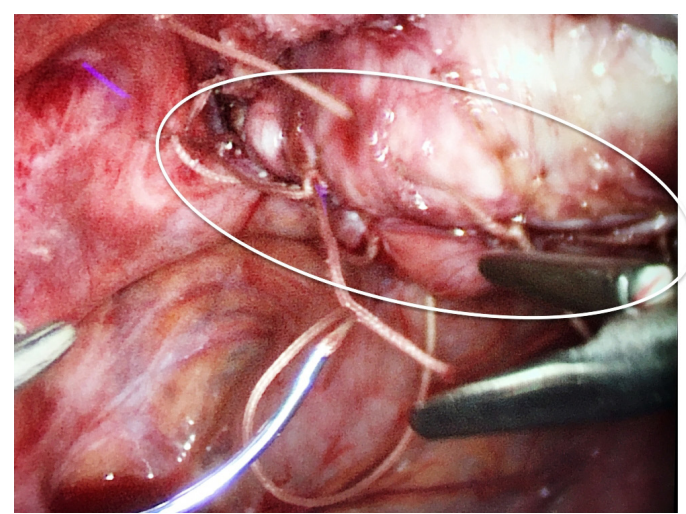

Figure 1 The vaginal cuff dehiscence (encircled) after laparoscopic closure with absorbable interrupted sutures.

vicryl 2-0 sutures before being inverted and a second layer of similar sutures inserted to effect a double layer of closure (figure 1). This was followed by the creation of an omental flap. The greater omentum was detached from the transverse colon while keeping its vascular pedicle connected at the side of the stomach. By dividing the omentum downwards in the midline, a long pediculated flap was constructed (figure 2). This omental flap was placed into the pelvis and was attached tension-free to the vaginal cuff closure by interrupted sutures vicryl 2-0 (figure 3). Standard preoperative antibiotics were administered. The duration of the procedure was $120 \mathrm{~min}$ and the length of hospitalisation was 1 day.

\section{Case 2}

A total laparoscopic hysterectomy combined with low anterior resection of the rectum and appendectomy for deep invasive endometriosis was performed in a 44-year-old nulliparous premenopausal woman. An ultrasonic dissection device (Sonicision) was used for this procedure. The same device was used during colpotomy. The vagina was closed laparoscopically using a 2-0 vicryl running suturing technique with clips. A standard single dose of preoperative antibiotic prophylaxis was administered. The surgery and postoperative course were uneventful.

Sixteen months later, she presented due to persistent complaints, especially of pain of the vaginal top during sexual intercourse. Her medical history was unremarkable except for surgery for endometriosis mentioned above. She had a normal bodyweight (body mass index 24), and besides a 10-pack year

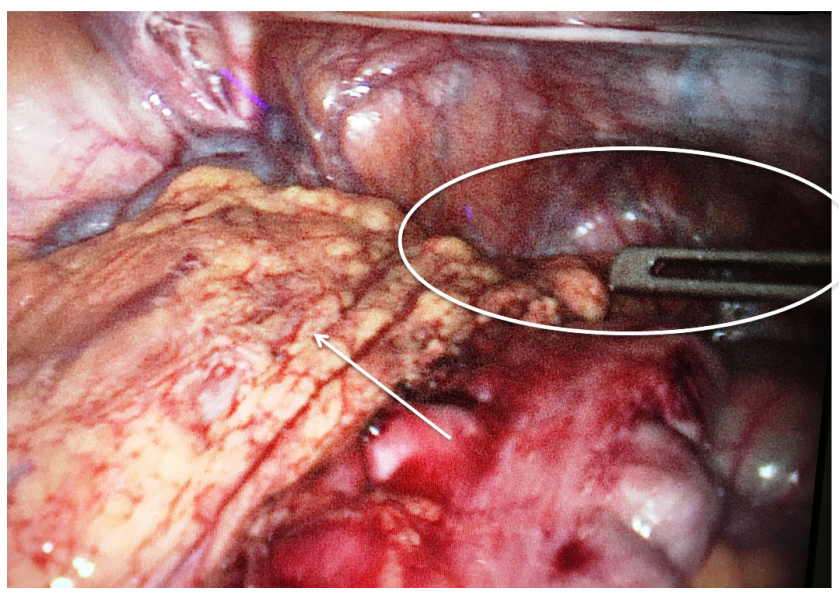

Figure 2 Mobilising the omental flap (arrow) to the pelvis (encircled).

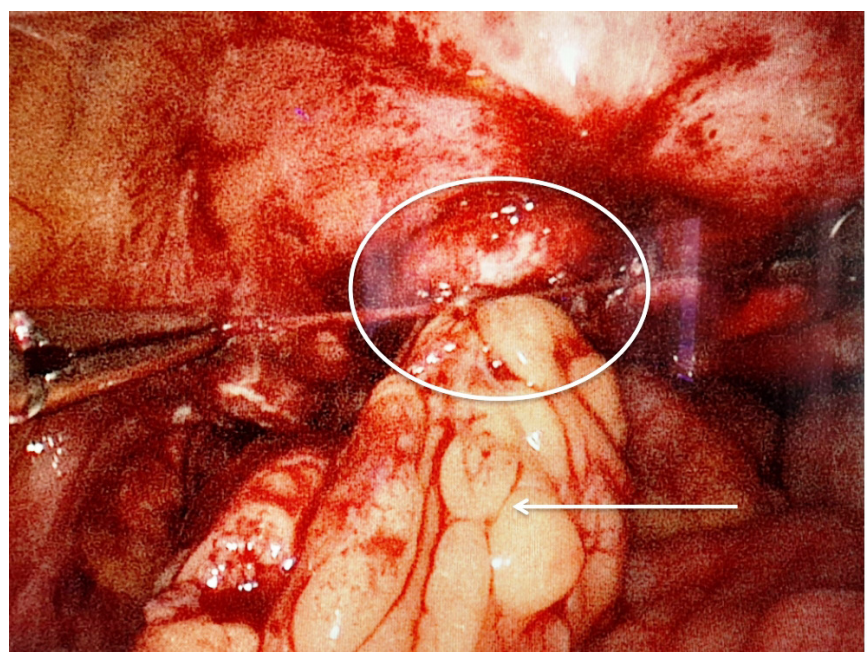

Figure 3 Placing the omental flap (arrow) into the pelvis and attaching it tension-free to the vaginal cuff (encircled).

history of cigarette smoking no risk factors for impaired wound healing were identified. She was planned for repeat surgery for endometriosis. Ovariectomy, coagulation of the infundibulopelvic ligament and laparoscopic excision of the vaginal vault were performed. After mobilisation of the bladder, the vaginal vault was excised with an ultrasonic excision system and closed laparoscopically with a vicryl 0 running suture. A standard single dose of preoperative antibiotic prophylaxis was administered. Histological analysis revealed inflammation of the vagina without evident endometriosis.

Ten weeks after surgery, she presented to our emergency department with severe abdominal pain after sexual intercourse. On examination, vaginal dehiscence was seen with exposure of fat tissue, probably omentum. Since the pain disappeared shortly after hospitalisation and no evisceration was seen, she was planned for a laparoscopic repair with an omental flap.

During laparoscopic repair the omentum was found to be stuck in the $1.5 \mathrm{~cm}$ vaginal dehiscence. First, the omentum was easily removed from the dehiscence. As the omentum was long enough to reach the vaginal cuff without traction, it was not necessary to create an omental flap as in the first case. The vaginal cuff was refreshed and interrupted vicryl 2-0 sutures were used to close the vaginal cuff and to attach the omentum onto it. A standard single dose of preoperative antibiotic prophylaxis was administered. The duration of the procedure was $40 \mathrm{~min}$ and hospitalisation was less than 1 day.

\section{TREATMENT}

\section{Vaginal bowel evisceration}

Vaginal cuff dehiscence complicated by evisceration of abdominal organs is a surgical emergency as organs prolapsing through the vagina are at risk of ischaemia. Initial management should focus on protecting the eviscerated organs, mostly the distal ileum. Antibiotics should be administered to minimise the risk of intraperitoneal infection. If careful attempt reducing the eviscerated organs fails, prompt surgical intervention is indicated. To protect the bowel, it can be wrapped in normal saline dressings and the patient should be placed in Trendelenburg position. Thorough examination and assessment of viability is important since bowel injury may require bowel resection and a different surgical approach. If the eviscerated bowel is readily reducible and appears viable, a vaginal repair should be 
considered. When bowel injury is suspected, exploratory laparoscopy or laparotomy is indicated. Other causes like haematoma or abscess should be ruled out.

\section{Omental flap and procedure}

The greater omentum consists of a double fold of mesothelial cells attached to the stomach and to the transverse colon. Besides the fat cells, the greater omentum is well vascularised and contains abundant lymphoid tissue. Because of its unique functional and anatomical characteristics, the omentum is used as a free or pedunculated flap in surgery in many ways, from reconstructing soft tissue defects to support of impaired wound healing following radiotherapy.

There is only one report ${ }^{1}$ of two cases of gynaecological oncological surgery in which a pedunculated omental flap is used to repair a vaginal cuff dehiscence. One patient presented 15 months after the omental flap repair, again with a vaginal cuff dehiscence following sexual intercourse. The other patient was 74 years old and nothing was reported about her sexual activity. Cuff dehiscence followed brachytherapy, which was not resumed after repair. The technique used differs slightly compared with our approach. They used a combined laparoscopic and vaginal approach, that is, identifying the omentum by the vaginal route after laparoscopic mobilisation and incorporating it into the vaginal cuff by vaginal closure. We performed the procedure completely laparoscopically: doublelayer suturing of the vaginal cuff, mobilisation of the omental flap and attachment of the omental flap to the vaginal cuff with laparoscopic sutures as well.

\section{OUTCOME AND FOLLOW-UP}

\section{Case 1}

At the postoperative check-up 6 weeks after surgery, an intact vaginal cuff was seen during internal examination. Ultrasound revealed a significant thicker vaginal cuff of $6.6 \mathrm{~mm}$ compared with $1.0 \mathrm{~mm}$ before the laparoscopic repair. She was told she could resume sexual intercourse after 3 months.

The patient was subsequently reviewed at 18 months post surgery and had no problems, having resumed sexual activity 3 months earlier.

\section{Case 2}

At the postoperative check-up 6 weeks after surgery, an intact vaginal cuff was seen during internal examination. She was told she could resume sexual intercourse after 3 months.

The patient was subsequently reviewed at 14 months post surgery and had no problems, having resumed sexual activity 11 months earlier.

\section{DISCUSSION}

Vaginal cuff dehiscence, also named vaginal cuff rupture or separation, is a rare but potentially severe complication after hysterectomy. Bowel evisceration, but other expulsed organs as well, can lead to serious complications including necrosis and sepsis. Prompt medical intervention is indicated. In recurrent vaginal cuff dehiscence management options for repair are limited.

\section{Incidence}

Studies on the subject are limited by the rarity, retrospective nature and reporting bias especially for recurrent cuff dehiscence. Recurrent vaginal cuff dehiscence is reported in case reports after surgery and radiotherapy for malignant diseases.
In a previous study from Blikkendaal et al ${ }^{2}$ on vaginal cuff dehiscence in our clinic, an incidence of vaginal cuff dehiscence of $2.4 \%$ was reported. Patients were included after total laparoscopic hysterectomy for benign or premalignant indications. The vagina was closed by laparoscopic running suture as in our presented cases. During this 7-year study period, 331 patients were included and no recurrent vaginal cuff dehiscence occurred.

\section{Risk factors and aetiology}

Many studies have attempted to identify risk factors for vaginal cuff dehiscence, all limited by the rarity of the event and their retrospective character. ${ }^{3}{ }^{4}$ Risk factors suggested are postmenopausal status, impaired wound healing due to infection or haematoma, excessive pressure, sexual intercourse, cigarette smoking, pelvic radiation therapy and mode of surgery. Some studies suggest laparoscopic hysterectomy increases the risk of vaginal dehiscence, although a recent randomised controlled trial ${ }^{5}$ shows the opposite. Unique features hypothesised to increase the risk of vaginal dehiscence in laparoscopic hysterectomy are electrosurgery used for colpotomy, magnification during laparoscopy, suture material and laparoscopic suturing requiring advanced skills. Risk factors specific to our cases might be impaired tissue vascularisation as a result of the repeated surgery (electrosurgery/ultrasonic) and endometriosis or inflammation itself.

We report the successful repair of recurrent vaginal cuff dehiscence after surgery for endometriosis by employing an omental flap. Vaginal cuff dehiscence is a potentially severe complication with high emotional and social impact. Management options are limited but often effective. Although the aetiology of vaginal cuff dehiscence remains unclear, we hypothesise that in our cases endometriosis itself and repetitive use of energy sources have contributed to impaired tissue healing. In this perspective using an omental flap with its immunological and angiogenic characteristics would theoretically improve tissue healing. Since an omental flap is widely used in reconstructive surgery, we think it should be considered as a treatment option if initial management of vaginal cuff dehiscence fails.

\section{Learning points}

- Vaginal cuff dehiscence is a potentially severe complication.

- Emotional and sexuosocial impact is high, especially in sexually active women.

- Management options for recurrent vaginal cuff dehiscence are limited.

- A laparoscopic repair using an omental flap to improve tissue healing should be considered as a treatment option.

Contributors G-PF wrote and edited the manuscript. The case was under the care of JR, MW and JE. They all substantially contributed to the manuscript and revising it critically.

Funding The authors have not declared a specific grant for this research from any funding agency in the public, commercial or not-for-profit sectors.

Competing interests None declared.

Patient consent for publication Obtained.

Provenance and peer review Not commissioned; externally peer reviewed.

Open access This is an open access article distributed in accordance with the Creative Commons Attribution Non Commercial (CC BY-NC 4.0) license, which permits others to distribute, remix, adapt, build upon this work non-commercially, and license their derivative works on different terms, provided the original work 
is properly cited and the use is non-commercial. See: http://creativecommons.org/ licenses/by-nc/4.0/.

\section{ORCID iD}

Gerard-Peter Frank http://orcid.org/0000-0003-4640-8776

\section{REFERENCES}

1 Narducci F, Sonoda Y, Lambaudie E, et al. Vaginal evisceration after hysterectomy: the repair by a laparoscopic and vaginal approach with a omental flap. Gynecol Oncol 2003;89:549-51.
2 Blikkendaal MD, Twijnstra ARH, Pacquee SCL, et al. Vaginal cuff dehiscence in laparoscopic hysterectomy: influence of various suturing methods of the vaginal vault. Gynecol Surg 2012;9:393-400.

3 Uccella S, Ceccaroni M, Cromi A, et al. Vaginal cuff dehiscence in a series of 12,398 hysterectomies: effect of different types of colpotomy and vaginal closure. Obstet Gynecol 2012;120:516-23.

4 Hur H-C, Lightfoot M, McMillin MG, et al. Vaginal cuff dehiscence and evisceration: a review of the literature. Curr Opin Obstet Gynecol 2016;28:297-303.

5 Uccella S, Malzoni M, Cromi A, et al. Laparoscopic vs transvaginal cuff closure after total laparoscopic hysterectomy: a randomized trial by the Italian Society of gynecologic endoscopy. Am J Obstet Gynecol 2018;218:500.e1-500.e13.

Copyright 2021 BMJ Publishing Group. All rights reserved. For permission to reuse any of this content visit

https://www.bmj.com/company/products-services/rights-and-licensing/permissions/

BMJ Case Report Fellows may re-use this article for personal use and teaching without any further permission.

Become a Fellow of BMJ Case Reports today and you can:

- Submit as many cases as you like

- Enjoy fast sympathetic peer review and rapid publication of accepted articles

- Access all the published articles

Re-use any of the published material for personal use and teaching without further permission

\section{Customer Service}

If you have any further queries about your subscription, please contact our customer services team on +44 (0) 2071111105 or via email at support@bmj.com.

Visit casereports.bmj.com for more articles like this and to become a Fellow 